\title{
Robust Hydrogen-Evolving Electrocatalyst from Heterogeneous Molybdenum Disulfide-Based Catalyst
}

Jingying Sun, ${ }^{1,2}$ Fei Tian, ${ }^{2}$ Fang Yu, ${ }^{1,3 *} \mathrm{Ze}$ Yang, ${ }^{2}$ Bo Yu, ${ }^{4}$ Shuo Chen, ${ }^{2 *}$ Zhifeng Ren, ${ }^{2}$ and Haiqing $\mathrm{Zhou}^{1,3 *}$

${ }^{1}$ Key Laboratory of Low-Dimensional Quantum Structures and Quantum Control Ministry of Education, School of Physics and Electronics, Hunan Normal University, Changsha 410081, China

${ }^{2}$ Department of Physics and TcSUH, University of Houston, Houston, Texas 77204, United States

${ }^{3}$ Key Laboratory for Matter Microstructure and Function of Hunan Province, Hunan Normal University, Changsha 410081, China

${ }^{4}$ Ningbo Fengcheng Advanced Energy Materials Research Institute, Ningbo, Zhejiang 315500, China

*Fang Yu, E-mail address: fyu@hunnu.edu.cn;

*Shuo Chen, E-mail address: schen34@uh.edu;

*Hiaqing Zhou, E-mail address: hqzhou@ hunnu.edu.cn. 


\section{Experimental details}

Chemicals. Cobalt (II) nitrate hexahydrate $\left[\mathrm{Co}\left(\mathrm{NO}_{3}\right)_{2} \cdot 6 \mathrm{H}_{2} \mathrm{O}, 98 \%\right.$, Sigma-Aldrich], nickel (II) nitrate hexahydrate $\left[\mathrm{Ni}\left(\mathrm{NO}_{3}\right)_{2} \cdot 6 \mathrm{H}_{2} \mathrm{O}, 98 \%\right.$, Sigma-Aldrich], N,N-dimethylformamide (DMF) $\left[\left(\mathrm{CH}_{3}\right)_{2} \mathrm{NC}(\mathrm{O}) \mathrm{H}\right.$, anhydrous, 99.8\%, Sigma-Aldrich], ammonium fluoride $\left(\mathrm{NH}_{4} \mathrm{~F}\right.$, 99.99\%, Sigma-Aldrich), ammonium tetrathiomolybdate $\left[\left(\mathrm{NH}_{4}\right)_{2} \mathrm{MoS}_{4}, 99.97 \%\right.$, Sigma-Aldrich], selenium powder (Se, 99.99\%, Sigma-Aldrich), molybdenum disulfide $\left(\mathrm{MoS}_{2}, 99.995 \%\right.$, Sigma-Aldrich), urea $\left(\mathrm{NH}_{2} \mathrm{CONH}_{2}\right.$, Sigma-Aldrich), sulfuric acid $\left(\mathrm{H}_{2} \mathrm{SO}_{4}\right.$, ACS 95.0-98.0\%, Alfa Aesar), hydrochloric acid (HCl, ACS 37\%, Sigma-Aldrich), Ni foam (thickness: $1.6 \mathrm{~mm})$, graphite foil (Alfa Aesar), and Pt wire ( $\mathrm{CH}$ Instruments) were used for synthesis and measurements. The aqueous solution was prepared with deionized water (HHitech Master-S15, resistivity: 18.2 $\mathrm{M} \Omega \cdot \mathrm{cm})$. All of the chemicals were used without further purification.

Characterizations. Characterizations were carried out using field-emission scanning electron microscopy (SEM, LEO 1525) with an accelerating voltage of $10 \mathrm{kV}$, high resolution transmission electron microscopy (TEM, JEOL 2010F) with an accelerating voltage of $200 \mathrm{kV}$, powder X-ray diffraction (XRD, Rigaku SmartLab diffractometer) with a $\mathrm{Cu} \mathrm{K \alpha}$ source $(36 \mathrm{kV}, 20 \mathrm{~mA}, \lambda=1.5418 \AA$ ), and X-ray photoelectron spectroscopy (XPS, PHI Quanter) with a Al Ka source.

Electrochemical measurements. All the electrochemical measurements were carried out at ambient conditions via a three-electrode setup in $0.5 \mathrm{M} \mathrm{H}_{2} \mathrm{SO}_{4}$ solution on an electrochemical workstation (Biologic SP-200). The saturated calomel electrode (SCE) was used as the reference electrode, graphite foil or Pt wire worked as the counter electrode, and the as-prepared catalysts were directly connected with the working 
electrode. All of the measured potentials were calibrated to reversible hydrogen electrode (RHE) potentials. Linear sweep voltammetry (LSV) measurements were conducted with a scan rate of $2 \mathrm{mV} \mathrm{s}^{-1}$ over the potentials range from 0.05 to $-0.30 \mathrm{~V}$ (vs. RHE) to reveal the electrochemical activity of the catalysts. The electrochemical impedance spectroscopy (EIS) spectra were implemented at the frequency range of $100 \mathrm{kHz}$ to $0.1 \mathrm{~Hz}$ with an amplitude of $-0.15 \mathrm{~V}$ (vs. RHE) with oscillations of $10 \mathrm{mV}$. The electrochemical stability was tested in the potential range ( 0.05 to $-0.15 \mathrm{~V}$ vs. RHE) for 2000 cyclic voltammetry (CV) cycles at a scan rate of $100 \mathrm{mV} \mathrm{s}^{-1}$. The time-dependent durability was performed at fixed potentials of 57, 102, and $146 \mathrm{mV}$ (vs. RHE) for response current densities of 10, 100, and $500 \mathrm{~mA} \mathrm{~cm}^{-2}$, respectively, over $25 \mathrm{~h}$, with a $\mathrm{Pt}$ wire as counter electrode.

Evaluation of turnover frequency (TOF) for different catalysts. Turnover frequency (TOF) refers to the number of reacted molecules per surface active site per time for a catalytic reaction. The per-site TOF and the active-site density for the electrodes $\mathrm{NiCoSe}_{2}, \mathrm{MoS}_{2} / \mathrm{NiCoSe}_{2}$, and $\mathrm{MoS}_{1.5} \mathrm{Se}_{0.5} / \mathrm{NiCoSe}_{2}$ were experimentally measured in an electrochemical way. ${ }^{1} \mathrm{CV}$ curves of these three catalysts (Figure S4a-c, Supporting Information) were recorded in $1 \mathrm{M}$ phosphate-buffered saline (1M PBS, the $\mathrm{pH}$ value was around 7) electrolyte at a scan rate of $50 \mathrm{mV} \mathrm{s}^{-1}$ in the potential range from -0.2 to $0.6 \mathrm{~V} v$ s. RHE. In this region, no apparent redox was detected, implying one electron transfer process dominant. Thus, assuming that all of the surface-active sites are fully exposed to the electrolyte and that one electron is involved in both the reduction and oxidation processes simultaneously, the active site density on the surface can be directly derived from the absolute components of the voltammetric charge over the entire potential range divided by two (cathodic and anodic) and Faraday constant. The upper limit of the active sites can be estimated as follows.

$$
\mathrm{n}=\frac{Q}{2 F}
$$


where $F$ is the Faraday constant $\left(\sim 96,485 \mathrm{C} \mathrm{mol}^{-1}\right), \mathrm{n}$ is the active site density and $Q$ the total charge of the $\mathrm{CV}$ curve. The number of active sites is $5.2 \times 10^{-8}, 8.8 \times 10^{-8}$, and $9.2 \times 10^{-8} \mathrm{~mol} \mathrm{~cm}^{-2}$ for electrodes $\mathrm{NiCoSe}_{2}$, $\mathrm{MoS}_{2} / \mathrm{NiCoSe}_{2}$, and $\mathrm{MoS}_{1.5} \mathrm{Se}_{0.5} / \mathrm{NiCoSe}_{2}$, respectively. The per-site $\mathrm{TOF}$ can be calculated using the following equation.

$$
\mathrm{TOF}=\frac{1}{2} \frac{I}{n F}
$$

where $F$ is the Faraday constant, $n$ is the aforementioned active-site density, the coefficient $1 / 2$ is due to two electrons being required to produce one hydrogen molecule, and $I$ is the current of hydrogen evolution reaction (HER) in units of A, which can be extracted from the LSV curve (Figure S4d, Supporting Information). The TOF values of the catalysts varying with overpotential are presented in Figure S4e (Supporting Information). In particular, at the overpotential of $100 \mathrm{mV}$, the TOF values are $0.027,0.27$, and $0.75 \mathrm{~s}^{-1}$ for electrodes $\mathrm{NiCoSe}_{2}, \mathrm{MoS}_{2} / \mathrm{NiCoSe}_{2}$, and $\mathrm{MoS}_{1.5} \mathrm{Se}_{0.5} / \mathrm{NiCoSe}_{2}$, respectively. Even though there might be a significant uncertainty in the estimation of active sites and TOFs, the relative differences between two electrodes $\mathrm{MoS}_{1.5} \mathrm{Se}_{0.5} / \mathrm{NiCoSe}_{2}$ and $\mathrm{MoS}_{2} / \mathrm{NiCoSe}_{2}$ were expected to be revealed.

Estimation of electrochemically active surface areas (ECSA). The double-layer capacitance $\left(C_{d l}\right)$ is measured to explore the ECSA difference among different HER electrocatalysts, so as to figure out whether the overall electrode activity in acid is mainly contributed by the large electrochemical surface area or the intrinsic activity. Thus, since we aim to compare the catalytic activity of the electrocatalysts in acid in this work, the $C_{d l}$ or ECSA values were determined in the same electrolyte as the activity testing. For one certain material, the ECSA is supposed to be proportional to its electrochemical $C_{d l}$ at the solid-liquid interface. The $C_{d l}$ of an electrocatalyst is usually estimated by a simple $\mathrm{CV}$ method, ${ }^{2}$ which can be achieved by running $\mathrm{CV}$ 
curves within a non-Faradaic region in the working condition $\left(0.5 \mathrm{H}_{2} \mathrm{SO}_{4}\right.$ electrolyte $)$ at various scan rates. ${ }^{3}$ All of the CV curves (Figure S5a-c, Supporting Information) of the as-grown catalysts were conducted in the voltage bound between 0.1 to $0.2 \mathrm{~V}$ ( $v s$. RHE), so as to exclude the effect of electrochemically active surface areas. The scan rates from 100 to $10 \mathrm{mV} \mathrm{s}^{-1}$, from 55 to $10 \mathrm{mV} \mathrm{s}^{-1}$ and from 20 to $2 \mathrm{mV} \mathrm{s}^{-1}$ were chosen for electrode $\mathrm{NiCoSe}_{2}, \mathrm{MoS}_{2} / \mathrm{NiCoSe}_{2}$, and $\mathrm{MoS}_{1.5} \mathrm{Se}_{0.5} / \mathrm{NiCoSe}_{2}$, respectively, with 10 successive intervals. The $C_{d l}$ values of the electrodes were calculated by plotting the current density differences $\Delta j=\left(j_{\mathrm{a}}-j_{\mathrm{c}}\right)$ at intermediate value of the applied potential of $0.15 \mathrm{~V}(v s$. RHE) as a function of the scan rates (Figure S5d, Supporting Information), where the slope is twice that of $C_{d l}$. The $C_{d l}$ values are $8.05,19.83$, and $178.95 \mathrm{mF}$ $\mathrm{cm}^{-2}$ for electrodes $\mathrm{NiCoSe}_{2}, \mathrm{MoS}_{2} / \mathrm{NiCoSe}_{2}$, and $\mathrm{MoS}_{1.5} \mathrm{Se}_{0.5} / \mathrm{NiCoSe}_{2}$, respectively. 

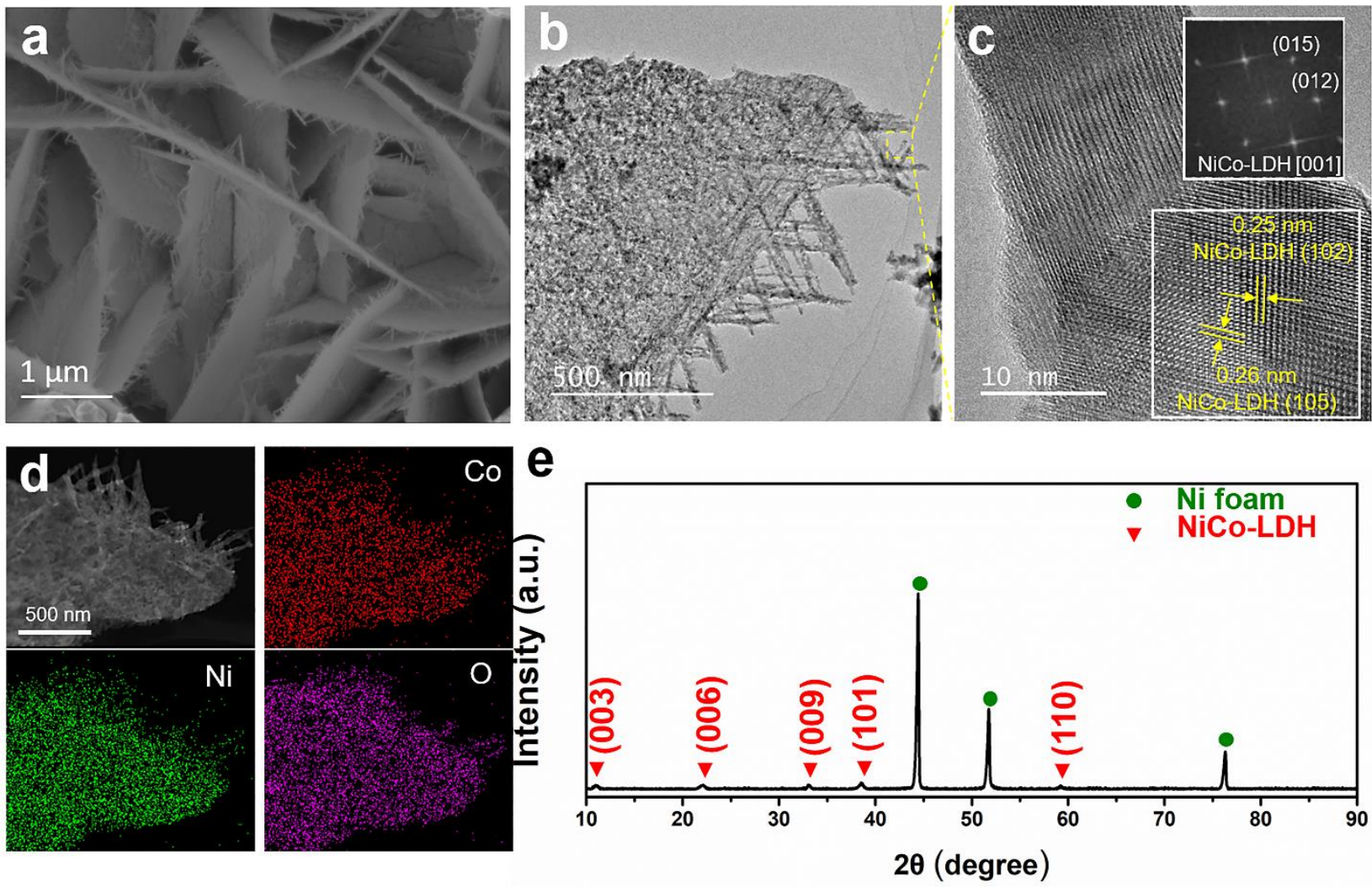

Figure S1. Characterization of NiCo-LDH nanosheets (a) SEM image, (b) TEM image, where the yellow dashed box indicates the area taken high-resolution TEM image, (c) high-resolution TEM image and the corresponding fast Fourier transform (FFT) pattern of the selected area (white box), (d) dark-field TEM image and corresponding energy-dispersive X-ray spectroscopy (EDS) elemental mappings of Co, $\mathrm{Ni}$, and $\mathrm{O}$ of the NiCo-LDH nanosheet, as well as (e) XRD pattern of NiCo-LDH/Ni foam sample. 

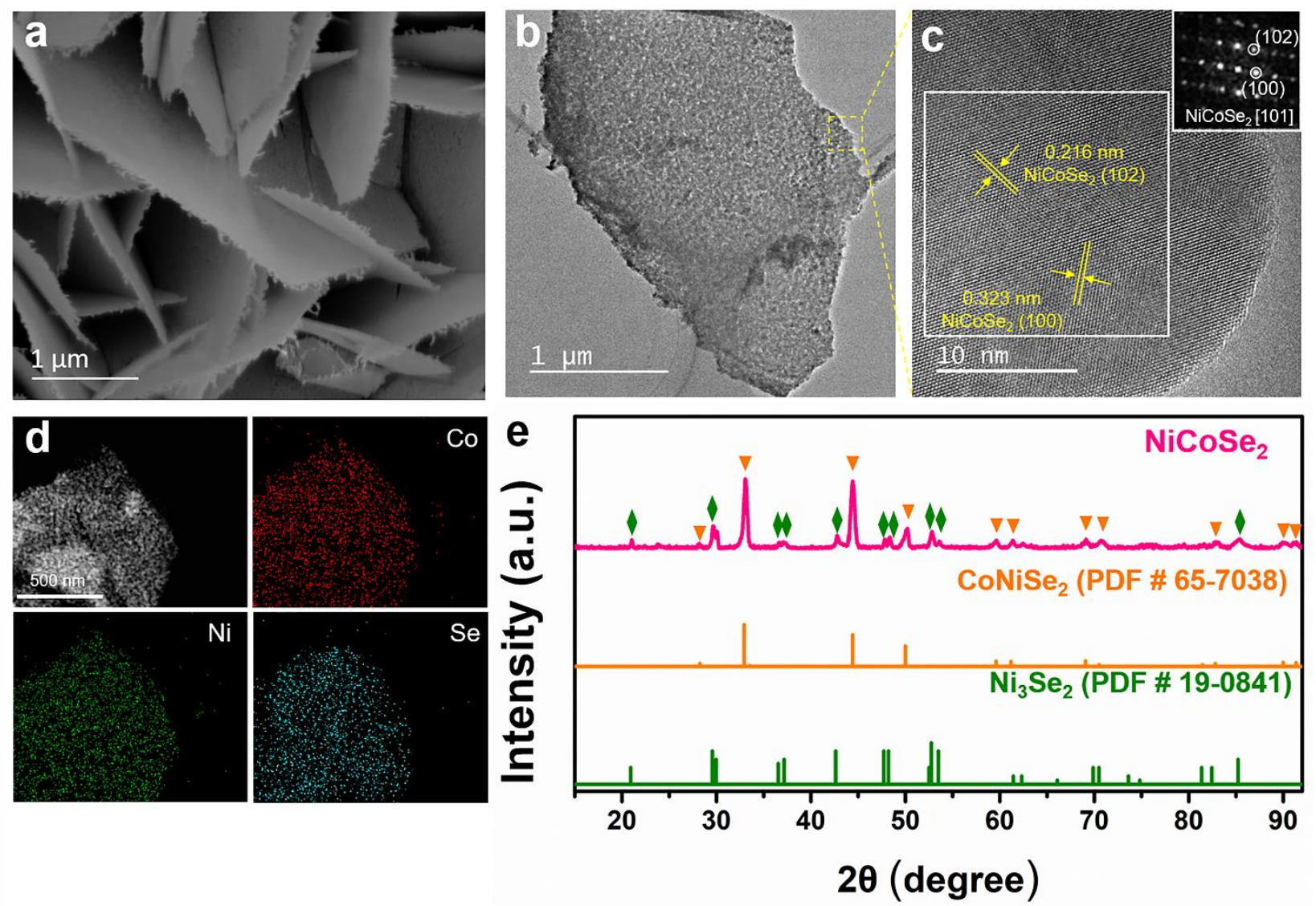

Figure S2. Characterization of $\mathrm{NiCoSe}_{2}$ nanosheet (a) SEM image, (b) TEM image, where the yellow dotted box corresponds to the area taken high-resolution TEM image, (c) high-resolution TEM image and the corresponding FFT pattern of the selected area (white box), (d) dark-field TEM image and corresponding EDS elemental mappings of $\mathrm{Co}, \mathrm{Ni}$, and $\mathrm{Se}$ for the $\mathrm{NiCoSe}_{2}$ nanosheet, as well as (e) XRD pattern for $\mathrm{NiCoSe}_{2} / \mathrm{Ni}$ foam. 

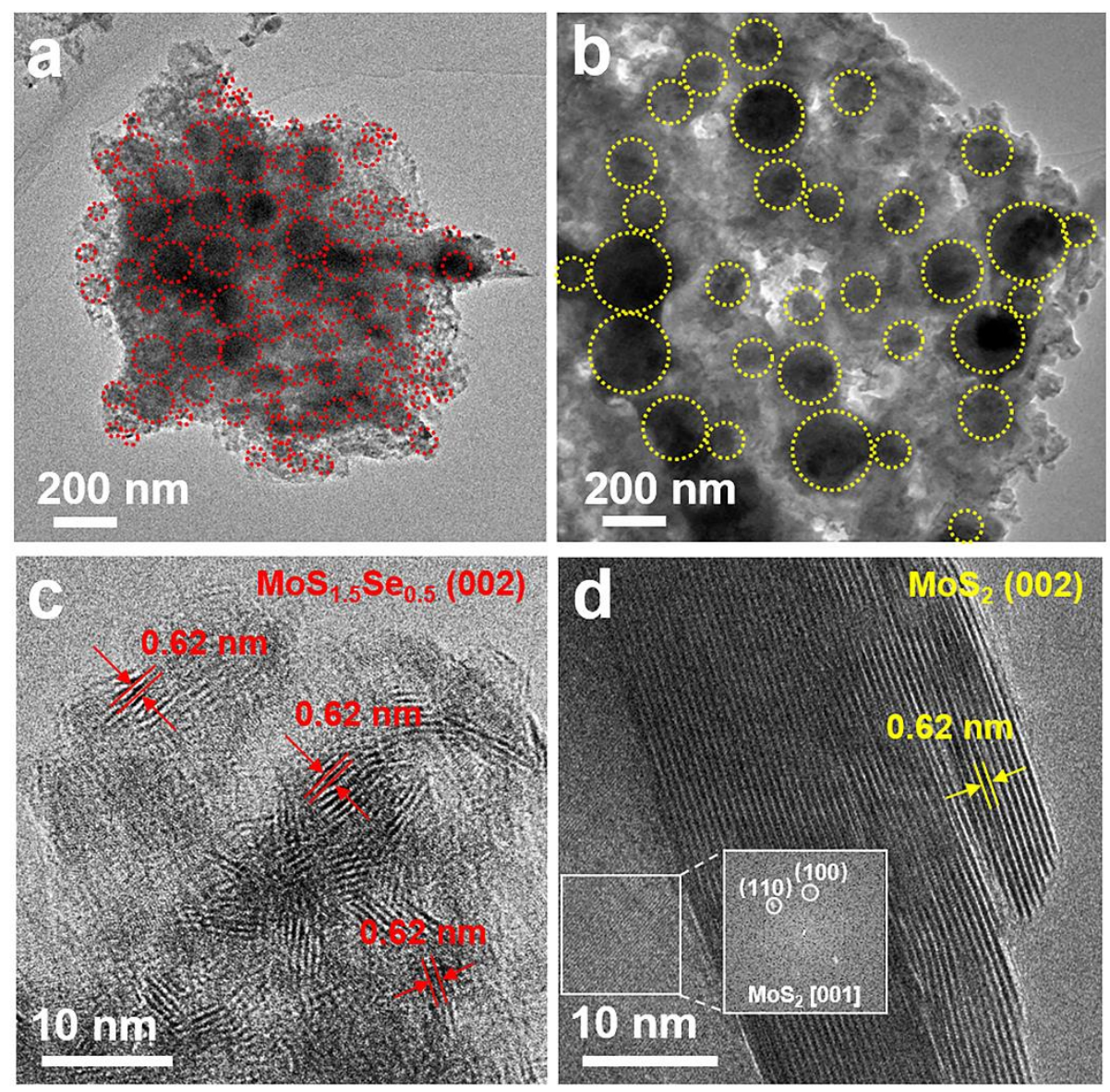

Figure S3. TEM images indicate the clusters of (a) $\mathrm{MoS}_{1.5} \mathrm{Se}_{0.5}$ and (b) pure $\mathrm{MoS}_{2}$, as well as the most characteristic interplanar spacings of the (002) facet for (c) $\mathrm{MoS}_{1.5} \mathrm{Se}_{0.5}$ and (d) pure $\mathrm{MoS}_{2}$. The white box in $\mathrm{d}$ is the corresponding FFT pattern of the selected area. The pure $\mathrm{MoS}_{2}$ sample is prepared from the $\mathrm{MoS}_{2} / \mathrm{NiCoSe}_{2}$ electrode. The $\mathrm{MoS}_{1.5} \mathrm{Se}_{0.5}$ sample shows more disordered and defective lattice fringes, and even less crystallinity. 

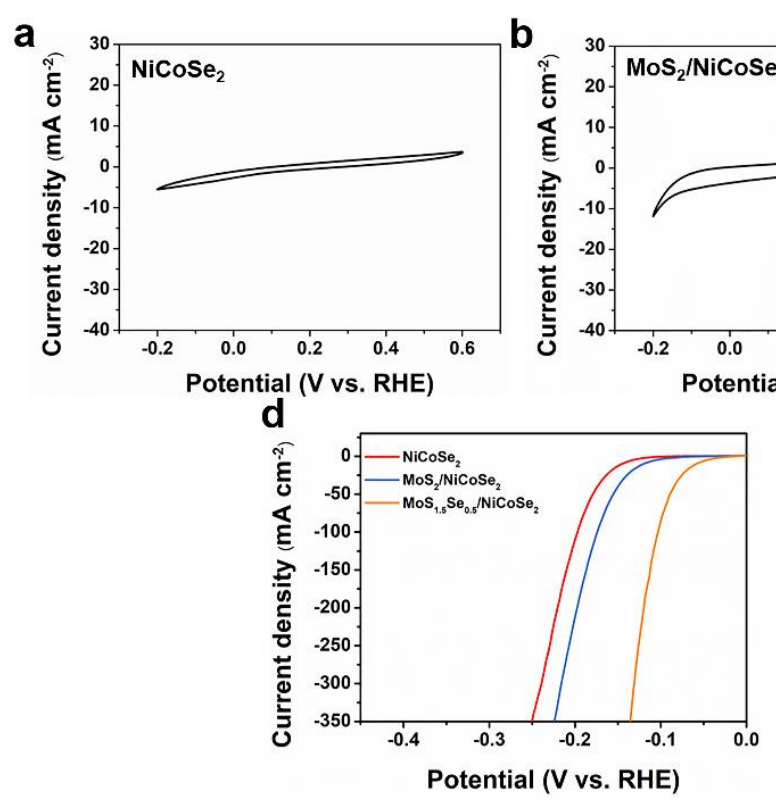

c
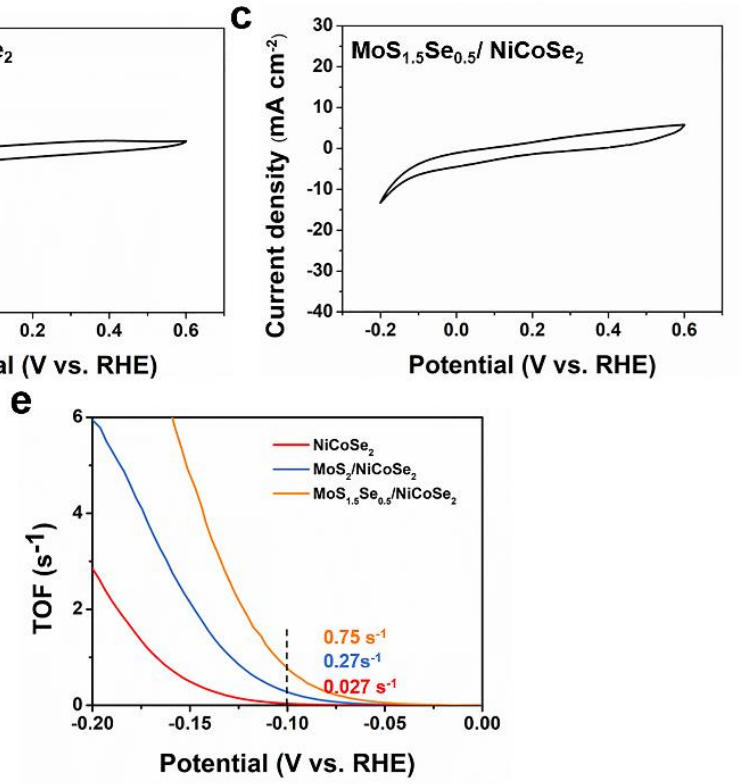

Figure S4. TOF measurements. CV curves of as-synthesized electrodes (a) $\mathrm{NiCoSe}_{2}$, (b) $\mathrm{MoS}_{2} / \mathrm{NiCoSe}_{2}$, and (c) $\mathrm{MoS}_{1.5} \mathrm{Se}_{0.5} / \mathrm{NiCoSe}_{2}$ tested in the potential range between -0.2 to $0.6 \mathrm{~V}$ (vs. RHE) in $1 \mathrm{M}$ PBS electrolyte $(\mathrm{pH}$ 7) at a scan rate of $50 \mathrm{mV} / \mathrm{s}$. (d) Polarization curves and (e) corresponding TOF values of electrodes $\mathrm{NiCoSe}_{2}, \mathrm{MoS}_{2} / \mathrm{NiCoSe}_{2}$, and $\mathrm{MoS}_{1.5} \mathrm{Se}_{0.5} / \mathrm{NiCoSe}_{2}$ varying with overpotential in $0.5 \mathrm{M} \mathrm{H}_{2} \mathrm{SO}_{4}$ solution. 

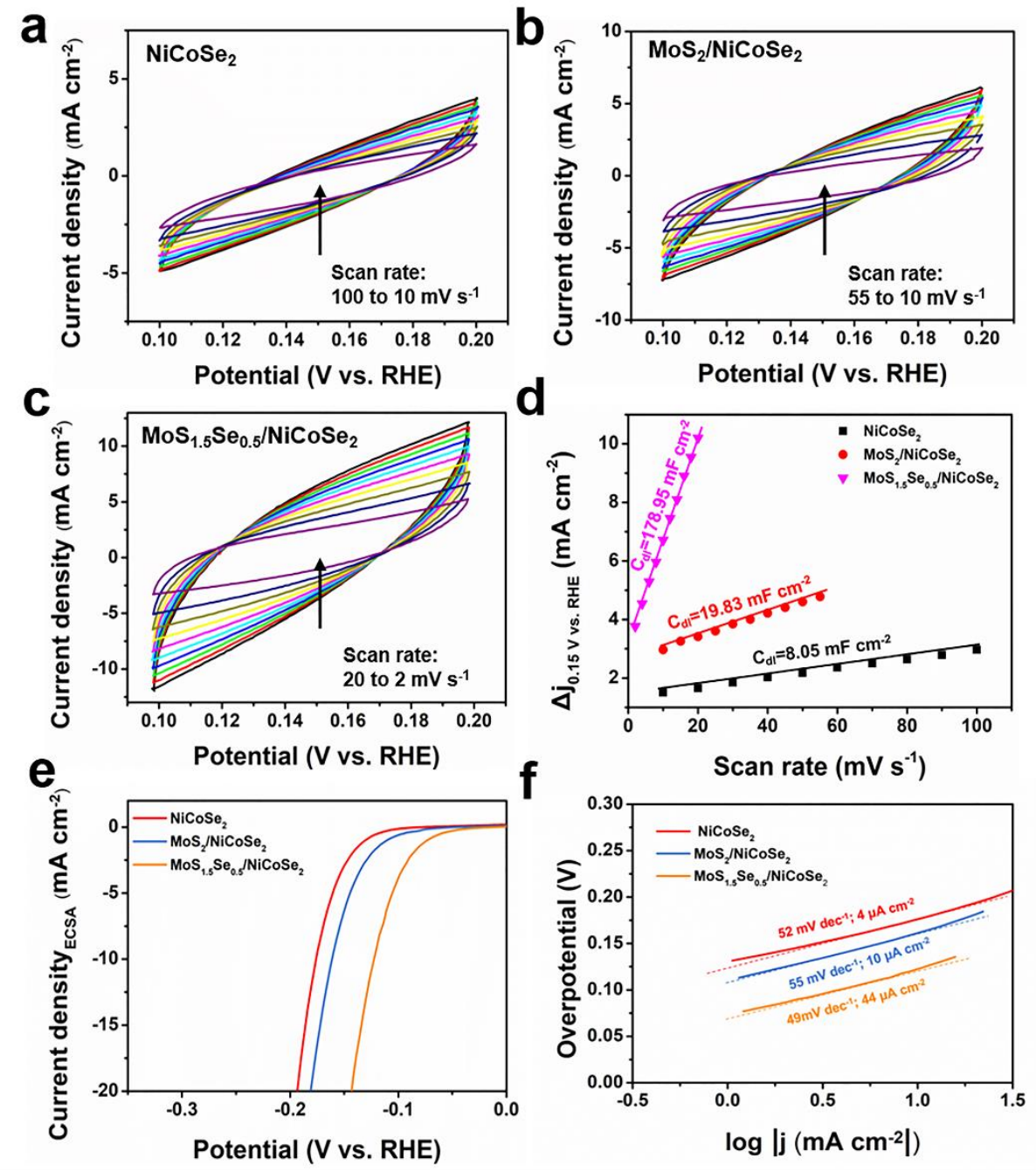

Figure S5. Double-layer capacitance $\left(C_{d l}\right)$ measurements. CVs of as-grown catalysts (a) $\mathrm{NiCoSe}_{2},(\mathrm{~b})$ $\mathrm{MoS}_{2} / \mathrm{NiCoSe}_{2}$, and (c) $\mathrm{MoS}_{1.5} \mathrm{Se}_{0.5} / \mathrm{NiCoSe}_{2}$ recorded at different potential scanning rates. The selected potential range with no faradic current occurring is from 0.1 to $0.2 \mathrm{~V}$ (vs. RHE). (d) Linear fitting of the capacitive currents of the various catalysts versus scan rates. (e) HER polarization curves of different catalysts normalized by the ECSAs, and the (f) corresponding Tafel plots. 
a

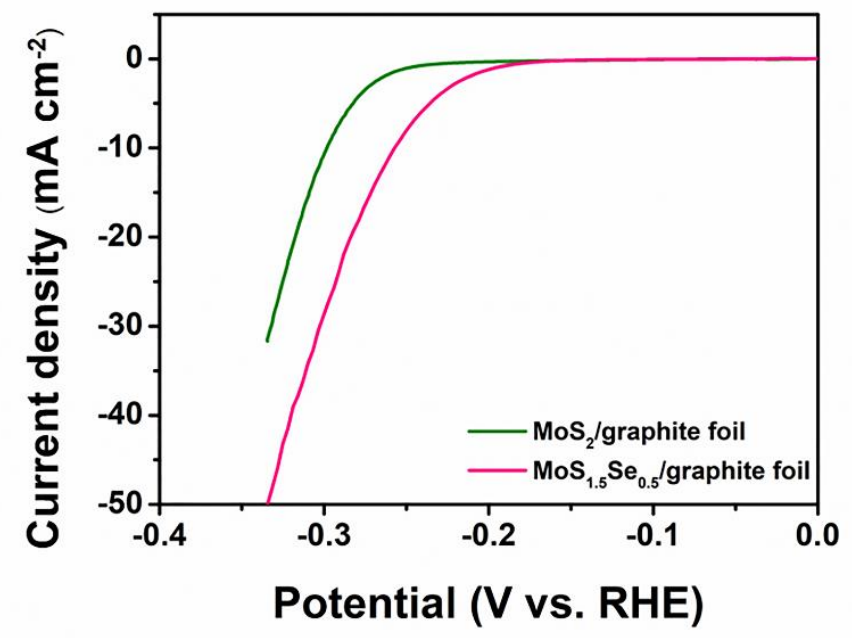

b

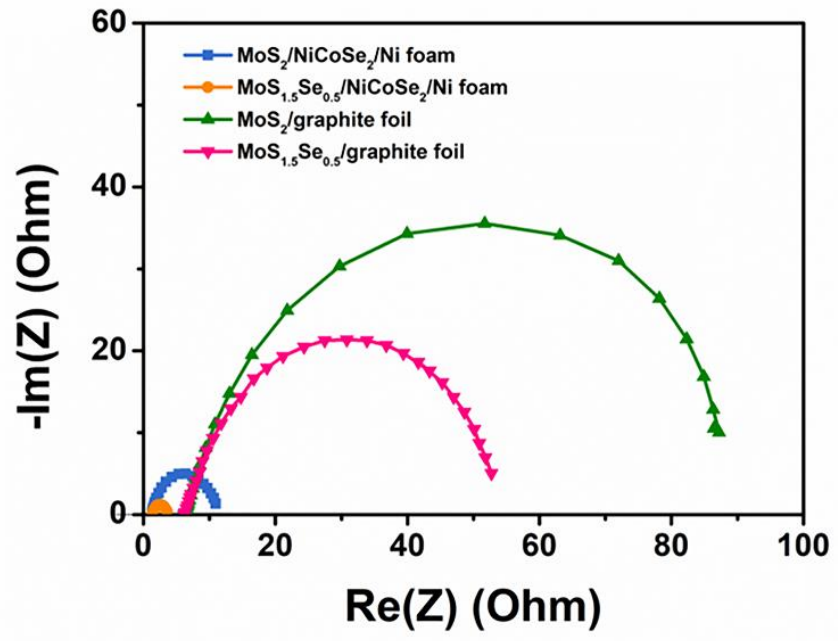

Figure S6. EIS measurements. (a) Polarization curves of $\mathrm{MoS}_{1.5} \mathrm{Se}_{0.5} /$ graphite foil and $\mathrm{MoS}_{2} /$ graphite foil electrodes, which were tested in $0.5 \mathrm{H}_{2} \mathrm{SO}_{4}$ solution with a scan rate of $2 \mathrm{mV} \mathrm{s}^{-1}$ in the potential range from 0 to $-0.34 \mathrm{mV}$ vs. RHE. (b) Nyquist plots of the electrodes $\mathrm{MoS}_{2} / \mathrm{NiCoSe}_{2} / \mathrm{Ni}$ foam, $\mathrm{MoS}_{1.5} \mathrm{Se}_{0.5} / \mathrm{NiCoSe}_{2} / \mathrm{Ni}$ foam, $\mathrm{MoS}_{2}$ /graphite foil, and $\mathrm{MoS}_{1.5} \mathrm{Se}_{0.5} /$ graphite foil at a potential of $-0.15 \mathrm{~V}$ with $10 \mathrm{mV}$ oscillation. Based on the EIS analysis, the series resistances $R_{\mathrm{S}}$ for these four electrodes $\mathrm{MoS}_{2} / \mathrm{NiCoSe}_{2} / \mathrm{Ni}$ foam, $\mathrm{MoS}_{1.5} \mathrm{Se}_{0.5} / \mathrm{NiCoSe}_{2} / \mathrm{Ni}$ foam, $\mathrm{MoS}_{2} /$ graphite foil, and $\mathrm{MoS}_{1.5} \mathrm{Se}_{0.5} /$ graphite foil are derived to be $1.41 \Omega, 1.39$ $\Omega, 6.22 \Omega$, and $6.18 \Omega$, respectively. Two reference electrodes with highly conductive graphite foil as substrate, $\mathrm{MoS}_{1.5} \mathrm{Se}_{0.5}$ /graphite foil and $\mathrm{MoS}_{2}$ /graphite foil, were prepared by the synthesis process similar to that of $\mathrm{MoS}_{1.5} \mathrm{Se}_{0.5} / \mathrm{NiCoSe}_{2} / \mathrm{Ni}$ foam and $\mathrm{MoS}_{2} / \mathrm{NiCoSe}_{2} / \mathrm{Ni}$ foam. 


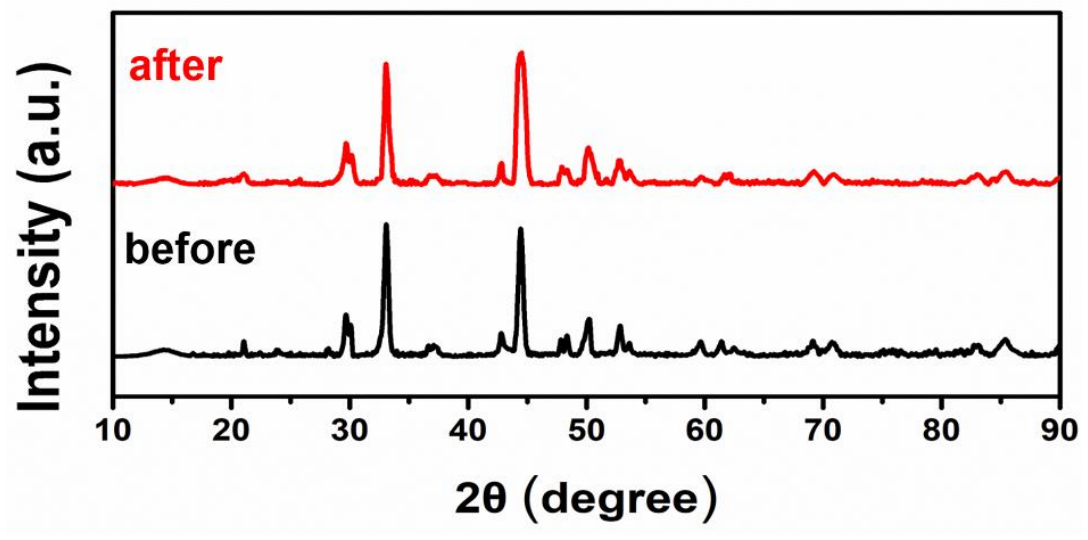

Figure S7. XRD patterns of the $\mathrm{MoS}_{1.5} \mathrm{Se}_{0.5} / \mathrm{NiCoSe}_{2}$ electrode before and after durability testing, where no phase change is observed. 

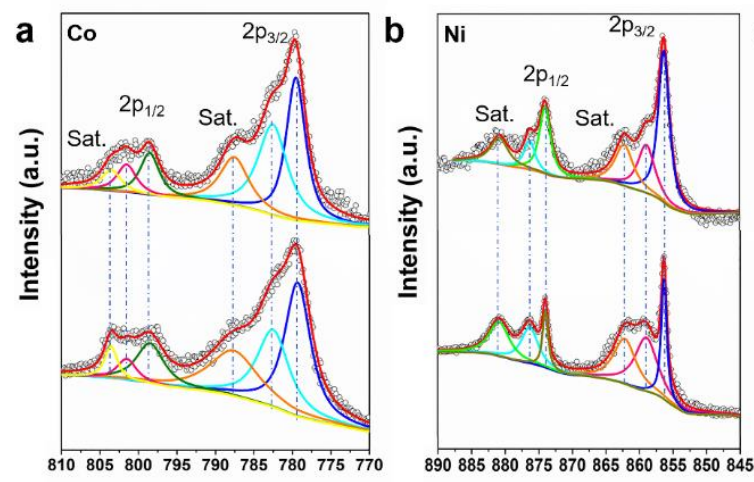

Binding energy $(\mathrm{eV})$

Binding energy (eV)
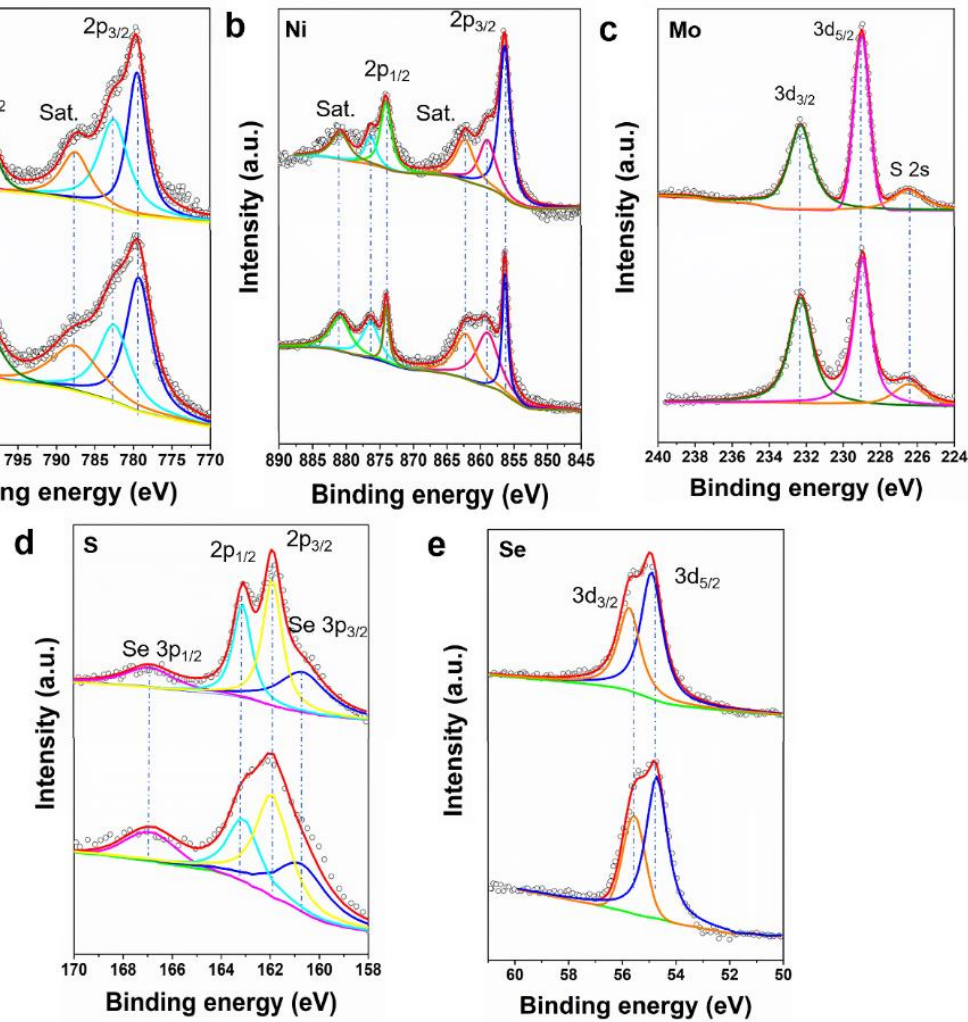

Figure S8. High-resolution XPS spectra of (a) Co 2p, (b) Ni 2p, (c) Mo 3d, (d) S 2p, and (e) Se 3d for heterostructured $\mathrm{MoS}_{1.5} \mathrm{Se}_{0.5} / \mathrm{NiCoSe}_{2}$ before (top) and after (bottom) stability testing, showing no changes in surface bonds. 

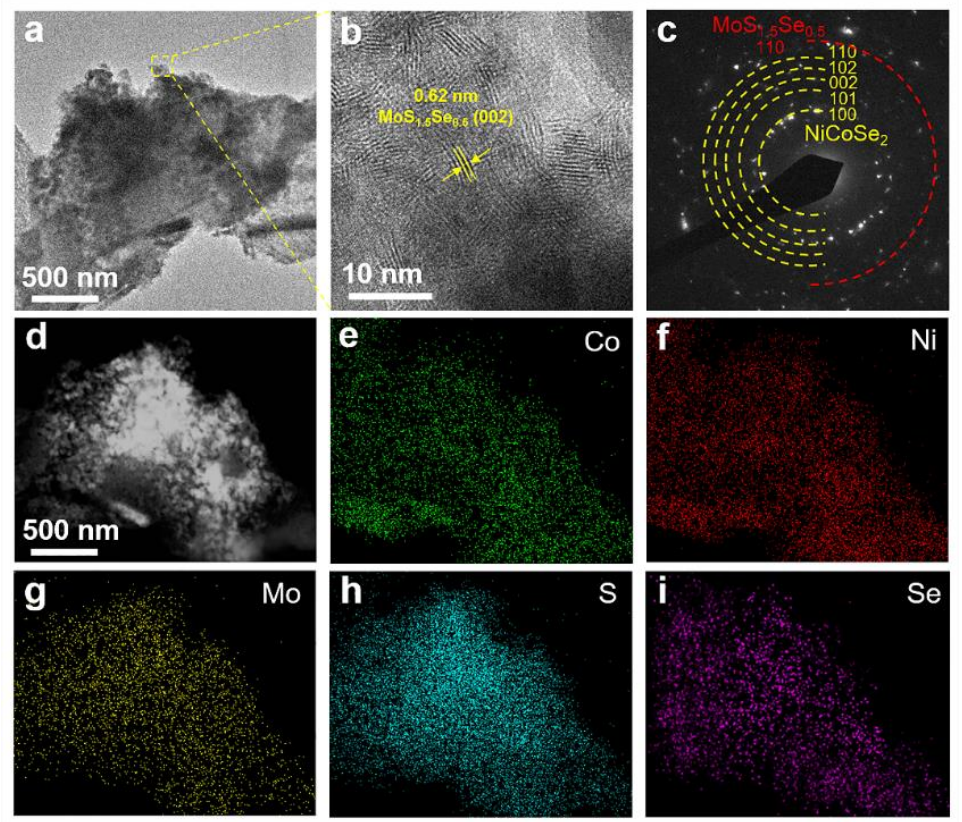

Figure S9. (a) TEM image, (b) high-resolution TEM image, where the yellow dashed box is related to the area taken high-resolution TEM image, (c) selected area electron diffraction (SAED) pattern, (d) dark-field TEM image, and (e-i) corresponding EDS elemental mappings for Co, Ni, Mo, S, and Se, respectively, of the $\mathrm{MoS}_{1.5} \mathrm{Se}_{0.5} / \mathrm{NiCoSe}_{2}$ nanosheets after $25 \mathrm{~h}$ durability testing. 


\section{Catalytic activity comparison}

Table S1. Comparison of the electrocatalytic activity among the as-prepared $\mathrm{MoS}_{1.5} \mathrm{Se}_{0.5} / \mathrm{NiCoSe}_{2}$ and recently reported non-precious catalysts with similar composition in $0.5 \mathrm{M} \mathrm{H}_{2} \mathrm{SO}_{4}$ electrolyte. Here, $\eta_{50}, \eta_{100}$, and $\eta_{200}$ are the overpotentials at the current densities of 50,100 , and $200 \mathrm{~mA} \mathrm{~cm}{ }^{-2}$, respectively; $j_{0}$ is the exchange current density; and $C_{d l}$ represents double-layer capacitance.

\begin{tabular}{|c|c|c|c|c|c|c|c|}
\hline Catalysts & $\begin{array}{c}\eta_{50} \\
(\mathrm{mV})\end{array}$ & $\begin{array}{c}\eta_{100} \\
(\mathrm{mV})\end{array}$ & $\begin{array}{c}\eta_{200} \\
(\mathrm{mV})\end{array}$ & $\begin{array}{c}j_{0} \\
\left(\mu \mathrm{A} \mathrm{cm}^{-2}\right)\end{array}$ & $\begin{array}{l}\text { Tafel slope } \\
\left.(\mathrm{mV} \mathrm{dec})^{-1}\right)\end{array}$ & $\begin{array}{c}C_{d l} \\
\left(\mathrm{mF} \mathrm{cm}^{-2}\right)\end{array}$ & Reference \\
\hline $\begin{array}{c}\mathrm{MoS}_{1.5} \mathrm{Se}_{0.5} \\
/ \mathrm{NiCoSe}_{2} \\
\end{array}$ & 88 & 102 & 119 & 424 & 48 & 178.95 & This work \\
\hline $\mathrm{CoS}_{2} / \mathrm{CoSe}_{2}$ & $122 *$ & 155 & NA & 37.8 & 33.6 & 28.3 & 4 \\
\hline $\mathrm{CoSe}_{2} / \mathrm{NiCoSe}_{2}$ & $>210$ & NA & NA & NA & 39.8 & 3.7 & 5 \\
\hline $\mathrm{MoS}_{2(1-x)} \mathrm{Se}_{2 x}$ & $190 *$ & $225^{*}$ & $240 *$ & NA & 65 & NA & 6 \\
\hline $\mathrm{Ni}_{0.33} \mathrm{Co}_{0.67} \mathrm{Se}_{2}$ & $95^{*}$ & NA & NA & 184 & 35 & 197 & 7 \\
\hline $\mathrm{Ni}_{0.7} \mathrm{Co}_{0.3} \mathrm{Se}_{2}$ & $110^{*}$ & $120^{*}$ & NA & NA & 31.6 & 0.058 & 8 \\
\hline $\mathrm{NiP}_{1.93} \mathrm{Se}_{0.07}$ & $>145$ & NA & NA & 100 & 41 & 27.6 & 9 \\
\hline $\mathrm{MoS}_{2} / \mathrm{CoSe}_{2}$ & $>130$ & NA & NA & 70.3 & 36 & NA & 10 \\
\hline $\mathrm{MoS}_{2} / \mathrm{CoS}_{2}$ & $117^{*}$ & 125 & NA & NA & 62 & 325 & 11 \\
\hline $\mathrm{MoSe}_{2} / \mathrm{NiSe}$ & $250^{*}$ & NA & NA & NA & 56 & 7.3 & 12 \\
\hline $\mathrm{MoS}_{2} / \mathrm{TiN}$ & $250 *$ & $275^{*}$ & NA & NA & 44.8 & NA & 13 \\
\hline $\mathrm{W}\left(\mathrm{Se}_{\mathrm{x}} \mathrm{S}_{1-\mathrm{x}}\right)_{2}$ & $310^{*}$ & NA & NA & 229 & 106 & 376 & 14 \\
\hline $\mathrm{MoS}_{\mathrm{x}} / \mathrm{N}-\mathrm{CNT}$ & $>125$ & NA & NA & 33.1 & 40 & NA & 15 \\
\hline Li-MoS 2 & $160^{*}$ & $175^{*}$ & 200 & 167 & 62 & 345 & 16 \\
\hline $\mathrm{MoS}_{2} / \mathrm{N}-\mathrm{rGO}$ & $110^{*}$ & NA & NA & 740 & 41.3 & 13.2 & 17 \\
\hline $\mathrm{MoS}_{2} / \mathrm{Mo}_{2} \mathrm{C}$ & $>80$ & NA & NA & 900 & 53 & 146 & 18 \\
\hline Se dope $\mathrm{MoS}_{2}$ & $>400$ & NA & NA & NA & 55 & NA & 19 \\
\hline $\mathrm{Ni}, \mathrm{Co}$ doped $\mathrm{MoS}_{2}$ & $>170$ & NA & NA & 9.1 & 51 & 11.7 & 20 \\
\hline
\end{tabular}




\begin{tabular}{|c|c|c|c|c|c|c|c|}
\hline NiWS/GC & $>250$ & NA & NA & 3.5 & 55 & NA & 21 \\
\hline WS $_{1.56} \mathrm{Se}_{0.44} \mathrm{NRs}-\mathrm{Li}$ & $>176$ & $\mathrm{NA}$ & $\mathrm{NA}$ & 25 & 68 & 6.98 & 22 \\
\hline $\mathrm{FeNiS}$ & $>150$ & $\mathrm{NA}$ & $\mathrm{NA}$ & 20 & 40 & 56.23 & 23 \\
\hline $\mathrm{MoS}_{2}$ & $>300$ & $\mathrm{NA}$ & $\mathrm{NA}$ & 1.6 & 61 & 2.15 & 24 \\
\hline $\mathrm{CoSe}_{2}$ & $170^{*}$ & 181 & $\mathrm{NA}$ & 4.9 & 40 & 14.1 & 25 \\
\hline $\mathrm{NiSe}_{2}$ & 175 & 196 & $213^{*}$ & 15.7 & 49 & 7.5 & 26 \\
\hline $\mathrm{HP}-\mathrm{NiSe}$ & $90 *$ & $101 *$ & $\mathrm{NA}$ & 612 & 43 & 239.6 & 27 \\
\hline $\mathrm{MoP} \mid \mathrm{S}$ & $100^{*}$ & 120 & $\mathrm{NA}$ & 570 & 50 & 12.2 & 28 \\
\hline
\end{tabular}

NA: The value is not available since it was not reported. * indicates that the value is extracted based on the data provided in the respective reference. 
Table S2. Comparison of the electrochemical performances among electrodes $\mathrm{NiCoSe}_{2}, \mathrm{MoS}_{2} / \mathrm{NiCoSe}_{2}$, and $\mathrm{MoS}_{1.5} \mathrm{Se}_{0.5} / \mathrm{NiCoSe}_{2}$. Tafel slope (geometric) $_{\text {and }}$ and $\mathrm{j}_{0 \text {,geometric }}$ are the Tafel slope and exchange current density normalized by the geometric area; Tafel slope $(\mathrm{ECSA})$ and $\mathrm{j}_{0, \text { normalized }}$ present the Tafel slope and exchange current density normalized by ECSA; ECSA was calculated by dividing double-layer capacitance $\left(C_{d l}\right)$.

\begin{tabular}{|c|c|c|c|c|c|c|}
\hline Catalyst & $\begin{array}{c}\text { Tafel } \\
\text { slope }(\text { geometric })^{\left(\mathbf{m V ~} \text { dec }^{-1}\right)}\end{array}$ & $\begin{array}{c}\text { jo,geometric } \\
\left(\mu \mathbf{A ~ c m}^{-2}\right)\end{array}$ & $\begin{array}{c}C_{d l} \\
\left(\mathrm{mF} \mathrm{cm}^{-2}\right)\end{array}$ & $\begin{array}{c}\text { Relative } \\
\text { surface } \\
\text { area }\end{array}$ & $\begin{array}{c}\text { Tafel } \\
\text { slope }(\text { ECSA) } \\
\left(\mathrm{mV} \mathrm{dec}^{-1}\right)\end{array}$ & $\begin{array}{l}\mathbf{j} 0 \text {,normalized } \\
\left(\mu \mathrm{A} \mathrm{cm}^{-2}\right)\end{array}$ \\
\hline $\mathrm{NiCoSe}_{2}$ & 43 & 12 & 8 & 1 & 52 & 4 \\
\hline $\mathrm{MoS}_{2} / \mathrm{NiCoSe}_{2}$ & 48 & 34 & 19 & 2.3 & 55 & 10 \\
\hline $\mathrm{MoSe}_{2} \mathrm{~S}_{2-\mathrm{x}} / \mathrm{NiCoSe}_{2}$ & 48 & 424 & 178 & 22 & 49 & 44 \\
\hline
\end{tabular}


Table S3. Comparison of the series resistances $\left(R_{\mathrm{S}}\right)$ of $\mathrm{MoS}_{2}$-based catalysts on various conductive substrates.

\begin{tabular}{|c|c|c|}
\hline Catalysts & $R_{\mathrm{S}}(\Omega)$ & Reference \\
\hline $\mathrm{MoS}_{1.5} \mathrm{Se}_{0.5} / \mathrm{NiCoSe}_{2} / \mathrm{Ni}$ foam & 1.4 & This work \\
\hline $\mathrm{MoS}_{1.5} \mathrm{Se}_{0.5} /$ graphite foil & 6.2 & This work \\
\hline n-BuLi treated $\mathrm{MoS}_{2} /$ graphite & 4 & 29 \\
\hline $\mathrm{MoS}_{2} /$ graphene foam & 9 & 30 \\
\hline Li-MoS $2 /$ carbon fiber paper & 1.80 & 31 \\
\hline $\mathrm{MoS}_{2} /$ Nitrogen-Doped rGO & 5 & 32 \\
\hline $\mathrm{MoSe}_{2} /$ carbon fiber paper & 2.4 & 33 \\
\hline Oxygen-incorporated $\mathrm{MoS}_{2} /$ glassy carbon & 4.7 & 34 \\
\hline $\mathrm{MoS}_{\mathrm{x}} / \mathrm{MWCNT}$ & 10 & 35 \\
\hline $\mathrm{MoS}_{2} /$ exfoliated rGO & 10.5 & 36 \\
\hline $\mathrm{MoS}_{2}-\mathrm{Mo}_{2} \mathrm{C} /$ carbon paper & 3 & 37 \\
\hline $\mathrm{MoS}_{2} / \mathrm{CoSe}_{2} /$ glassy carbon & 5 & 38 \\
\hline
\end{tabular}




\section{Reference}

(1) Merki, D.; Fierro, S.; Vrubel, H.; Hu, X. Amorphous Molybdenum Sulfide Films as Catalysts for Electrochemical Hydrogen Production in Water. Chem. Sci. 2011, 2, 1262-1267.

(2) McCrory, C. C.; Jung, S.; Peters, J. C.; Jaramillo, T. F. Benchmarking Heterogeneous Electrocatalysts for the Oxygen Evolution Reaction. J. Am. Chem. Soc. 2013, 135, 16977-16987.

(3) Yang, Y.; Fei, H.; Ruan, G.; Tour, J. M. Porous Cobalt-Based Thin Film as a Bifunctional Catalyst for Hydrogen Generation and Oxygen Generation. Adv. Mater. 2015, 27, 3175-3180.

(4) Guo, Y.; Shang, C.; Wang, E. An Efficient $\mathrm{CoS}_{2} / \mathrm{CoSe}_{2}$ Hybrid Catalyst for Electrocatalytic Hydrogen Evolution. J. Mater. Chem. A 2017, 5, 2504-2507.

(5) Park, S.-K.; Kim, J. K.; Kang, Y. C. Metal-Organic Framework-Derived CoSe $2 /\left(\mathrm{NiCo}_{2} \mathrm{Se}_{2}\right.$ Box-In-Box Hollow Nanocubes with Enhanced Electrochemical Properties for Sodium-Ion Storage and Hydrogen Evolution. J. Mater. Chem. A 2017, 5, 18823-18830.

(6) Yang, L.; Wang, W.; Fu, Q.; Zhang, J.; Xiang, B. $\mathrm{MoS}_{2(1-x)} \mathrm{Se}_{2 x}$ Nanobelts for Enhanced Hydrogen Evolution. Electrochim. Acta 2015, 185, 236-241.

(7) Xia, C.; Liang, H.; Zhu, J.; Schwingenschlögl, U.; Alshareef, H. N. Active Edge Sites Engineering in Nickel Cobalt Selenide Solid Solutions for Highly Efficient Hydrogen Evolution. Adv. Energy Mater. 2017, 7, 1602089-1602098.

(8) Wang, X.; Zheng, Y.; Yuan, J.; Shen, J.; Hu, J.; Wang, A.-j.; Wu, L.; Niu, L. Porous NiCo Diselenide Nanosheets Arrayed on Carbon Cloth as Promising Advanced Catalysts Used in Water Splitting. Electrochim. Acta 2017, 225, 503-513.

(9) Zhuo, J.; Cabán-Acevedo, M.; Liang, H.; Samad, L.; Ding, Q.; Fu, Y.; Li, M.; Jin, S. High-Performance Electrocatalysis for Hydrogen Evolution Reaction Using Se-Doped Pyrite-Phase Nickel Diphosphide Nanostructures. ACS Catal. 2015, 5, 6355-6361.

(10) Gao, M.-R.; Liang, J.-X.; Zheng, Y.-R.; Xu, Y.-F.; Jiang, J.; Gao, Q.; Li, J.; Yu, S.-H. An Efficient Molybdenum Disulfide/Cobalt Diselenide Hybrid Catalyst for Electrochemical Hydrogen Generation. Nat. Commun. 2015, 6, 5982.

(11) Ouyang, C.; Feng, S.; Huo, J.; Wang, S. Three-Dimensional Hierarchical $\mathrm{MoS}_{2} / \mathrm{CoS}_{2}$ Heterostructure Arrays for Highly Efficient Electrocatalytic Hydrogen Evolution. Green Energy Environ. 2017, 2, 134-141.

(12) Zhou, X.; Liu, Y.; Ju, H.; Pan, B.; Zhu, J.; Ding, T.; Wang, C.; Yang, Q. Design and Epitaxial Growth of $\mathrm{MoSe}_{2}-\mathrm{NiSe}$ Vertical Heteronanostructures with Electronic Modulation for Enhanced Hydrogen Evolution Reaction. Chem. Mater. 2016, 28, 1838-1846.

(13) Yu, M.; Zhao, S.; Feng, H.; Hu, L.; Zhang, X.; Zeng, Y.; Tong, Y.; Lu, X. Engineering Thin MoS Nanosheets on TiN Nanorods: Advanced Electrochemical Capacitor Electrode and Hydrogen Evolution Electrocatalyst. ACS Energy Lett. 2017, 2, 1862-1868.

(14) Zou, M.; Chen, J.; Xiao, L.; Zhu, H.; Yang, T.; Zhang, M.; Du, M. WSe 2 and W(Se $\left.\mathrm{S}_{1-\mathrm{x}}\right)_{2}$ Nanoflakes Grown on Carbon Nanofibers for the Electrocatalytic Hydrogen Evolution Reaction. J. Mater. Chem. A 2015, 3, 18090-18097.

(15) Li, D. J.; Maiti, U. N.; Lim, J.; Choi, D. S.; Lee, W. J.; Oh, Y.; Lee, G. Y.; Kim, S. O. Molybdenum Sulfide/N-Doped CNT Forest Hybrid Catalysts for High-Performance Hydrogen Evolution Reaction. Nano Lett. 2014, 14, 1228-1233.

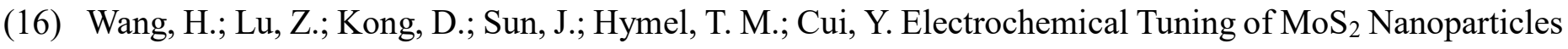
on Three-Dimensional Substrate for Efficient Hydrogen Evolution. ACS nano 2014, 8, 4940-4947.

(17) Tang, Y. J.; Wang, Y.; Wang, X. L.; Li, S. L.; Huang, W.; Dong, L. Z.; Liu, C. H.; Li, Y. F.; Lan, Y. Q. Molybdenum Disulfide/Nitrogen-Doped Reduced Graphene Oxide Nanocomposite with Enlarged 
Interlayer Spacing for Electrocatalytic Hydrogen Evolution. Adv. Energy Mater. 2016, 6, 1600116.

(18) Zhao, Z.; Qin, F.; Kasiraju, S.; Xie, L.; Alam, M. K.; Chen, S.; Wang, D.; Ren, Z.; Wang, Z.; Grabow, L. C; Bao, J. Vertically Aligned $\mathrm{MoS}_{2} / \mathrm{Mo}_{2} \mathrm{C}$ Hybrid Nanosheets Grown on Carbon Paper for Efficient Electrocatalytic Hydrogen Evolution. ACS Catal. 2017, 7, 7312-7318.

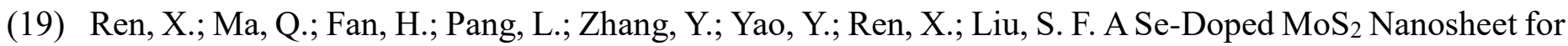
Improved Hydrogen Evolution Reaction. Chem. Commun. 2015, 51, 15997-16000.

(20) Yu, X. Y.; Feng, Y.; Jeon, Y.; Guan, B.; Lou, X. W.; Paik, U. Formation of Ni-Co-MoS2 Nanoboxes with Enhanced Electrocatalytic Activity for Hydrogen Evolution. Adv. Mater. 2016, 28, 9006-9011.

(21) Yang, L.; Wu, X.; Zhu, X.; He, C.; Meng, M.; Gan, Z.; Chu, P. K. Amorphous Nickel/Cobalt Tungsten Sulfide Electrocatalysts for High-Efficiency Hydrogen Evolution Reaction. Appl. Surf. Sci. 2015, 341, 149-156.

(22) Wang, F.; Li, J.; Wang, F.; Shifa, T. A.; Cheng, Z.; Wang, Z.; Xu, K.; Zhan, X.; Wang, Q.; Huang, Y; Jiang, C.; He, J. Enhanced Electrochemical $\mathrm{H}_{2}$ Evolution by Few-Layered Metallic $\mathrm{WS}_{2(1-\mathrm{x})} \mathrm{Se}_{2 \mathrm{x}}$ Nanoribbons. Adv. Funct. Mater. 2015, 25, 6077-6083.

(23) Long, X.; Li, G.; Wang, Z.; Zhu, H.; Zhang, T.; Xiao, S.; Guo, W.; Yang, S. Metallic Iron-Nickel Sulfide Ultrathin Nanosheets as A Highly Active Electrocatalyst for Hydrogen Evolution Reaction in Acidic Media. J. Am. Chem. Soc. 2015, 137, 11900-11903.

(24) Benson, J.; Li, M.; Wang, S.; Wang, P.; Papakonstantinou, P. Electrocatalytic Hydrogen Evolution Reaction on Edges of a Few Layer Molybdenum Disulfide Nanodots. ACS Appl. Mater. Interfaces 2015, 7, 14113-14122.

(25) Kong, D.; Wang, H.; Lu, Z.; Cui, Y. CoSe 2 Nanoparticles Grown on Carbon Fiber Paper: An Efficient and Stable Electrocatalyst for Hydrogen Evolution Reaction. J. Am. Chem. Soc. 2014, 136, 4897-4900.

(26) Zhou, H.; Wang, Y.; He, R.; Yu, F.; Sun, J.; Wang, F.; Lan, Y.; Ren, Z.; Chen, S. One-Step Synthesis of Self-Supported Porous $\mathrm{NiSe}_{2} / \mathrm{Ni}$ Hybrid Foam: An Efficient 3D Electrode for Hydrogen Evolution Reaction. Nano Energy 2016, 20, 29-36.

(27) Zhou, H.; Yu, F.; Liu, Y.; Sun, J.; Zhu, Z.; He, R.; Bao, J.; Goddard III. W. A.; Chen, S.; Ren, Z. Outstanding Hydrogen Evolution Reaction Catalyzed by Porous Nickel Diselenide Electrocatalysts. Energy Environ. Sci. 2017, 10, 1487-1492.

(28) Kibsgaard, J.; Jaramillo, T. F. Molybdenum Phosphosulfide: An Active, Acid-Stable, Earth-Abundant Catalyst for the Hydrogen Evolution Reaction. Angew. Chem. Int. Ed. 2014, 53, 14433-14437.

(29) Lukowski, M. A.; Daniel, A. S.; Meng, F.; Forticaux, A.; Li, L.; Jin, S. Enhanced Hydrogen Evolution Catalysis from Chemically Exfoliated Metallic $\mathrm{MoS}_{2}$ Nanosheets. J. Am. Chem. Soc. 2013, 135, 10274-10277.

(30) Liao, L.; Zhu, J.; Bian, X.; Zhu, L.; Scanlon, M. D.; Girault, H. H.; Liu, B. MoS 2 Formed on Mesoporous Graphene as a Highly Active Catalyst for Hydrogen Evolution. Adv. Funct. Mater. 2013, 23, 5326-5333.

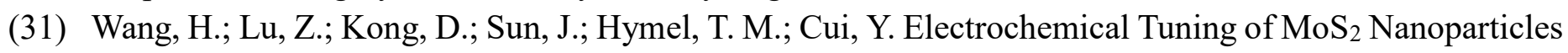
on Three-Dimensional Substrate for Efficient Hydrogen Evolution. ACS nano 2014, 8, 4940-4947.

(32) Tang, Y. J.; Wang, Y.; Wang, X. L.; Li, S. L.; Huang, W.; Dong, L. Z.; Liu, C. H.; Li, Y. F.; Lan, Y. Q. Molybdenum Disulfide/Nitrogen-Doped Reduced Graphene Oxide Nanocomposite with Enlarged Interlayer Spacing for Electrocatalytic Hydrogen Evolution. Adv. Energy Mater. 2016, 6, 1600116.

(33) Wang, H.; Kong, D.; Johanes, P.; Cha, J. J.; Zheng, G.; Yan, K.; Liu, N.; Cui, Y. MoSe 2 and WSe Nanofilms with Vertically Aligned Molecular Layers on Curved and Rough Surfaces. Nano Lett. 2013, 13, 3426-3433.

(34) Xie, J.; Zhang, J.; Li, S.; Grote, F.; Zhang, X.; Zhang, H.; Wang, R.; Lei, Y.; Pan, B.; Xie, Y. Controllable Disorder Engineering in Oxygen-Incorporated $\mathrm{MoS}_{2}$ Ultrathin Nanosheets for Efficient Hydrogen Evolution. J. Am. Chem. Soc. 2013, 135, 17881-17888. 
(35) Li, D. J.; Maiti, U. N.; Lim, J.; Choi, D. S.; Lee, W. J.; Oh, Y.; Lee, G. Y.; Kim, S. O. Molybdenum sulfide/N-doped CNT forest hybrid catalysts for high-performance hydrogen evolution reaction. Nano lett. 2014, 14, 1228-1233.

(36) Zheng, X.; Xu, J.; Yan, K.; Wang, H.; Wang, Z.; Yang, S. Space-Confined Growth of MoS 2 Nanosheets within Graphite: The Layered Hybrid of $\mathrm{MoS}_{2}$ and Graphene as an Active Catalyst for Hydrogen Evolution Reaction. Chem. Mater. 2014, 26, 2344-2353.

(37) Zhao, Z.; Qin, F.; Kasiraju, S.; Xie, L.; Alam, M. K.; Chen, S.; Wang, D.; Ren, Z.; Wang, Z.; Grabow, L. C. Vertically Aligned $\mathrm{MoS}_{2} / \mathrm{Mo}_{2} \mathrm{C}$ hybrid Nanosheets Grown on Carbon Paper for Efficient Electrocatalytic Hydrogen Evolution. ACS Catal. 2017, 7, 7312-7318.

(38) Gao, M.-R.; Liang, J.-X.; Zheng, Y.-R.; Xu, Y.-F.; Jiang, J.; Gao, Q.; Li, J.; Yu, S.-H. An Efficient Molybdenum Disulfide/Cobalt Diselenide Hybrid Catalyst for Electrochemical Hydrogen Generation. Nat. Commun. 2015, 6, 5982. 